\title{
Appropriate Learning Management for Students with Different Learning Styles within a Multicultural Society at State-run Universities in Thailand
}

\author{
Chidchanok Churngchow ${ }^{1,2}$, Narongsak Rorbkorb ${ }^{1}$, On-tip Petchurai ${ }^{1} \&$ Jirawat Tansakul $^{1}$ \\ ${ }^{1}$ Department of Educational Evaluation and Research, Faculty of Education, Prince of Songkla University, Thailand \\ ${ }^{2}$ Research Center for Educational Innovations and Teaching and Learning Excellence, Prince of Songkla University, \\ Thailand \\ Correspondence: Chidchanok Churngchow, Department of Educational Evaluation and Research, Faculty of \\ Education and Research Center for Educational Innovations and Teaching and Learning Excellence, Prince of \\ Songkla University, Thailand 94001. E-mail: chidchanok.c@psu.co.th
}

Received: June 20, 2019

Accepted: January 21, 2020

Online Published: January 30, 2020

doi:10.5430/ijhe.v9n2p200

URL: https://doi.org/10.5430/ijhe.v9n2p200

\begin{abstract}
This research aimed to discover appropriate learning management to suit students' different learning styles within a multicultural society at state-run universities using mixed methods research of explanatory design. A survey was first conducted followed by focus group discussions. It was found that the students consisted of all four types of learning styles: reflector, activist, theorist and pragmatist, while, reflectors were the majority group. The results also showed that students from different disciplines and types of high schools used different learning styles. However, the participants in the focus groups, especially the Muslim students, stated that they employed the pragmatic style as well as their dominant style. It is suggested that a teaching style incorporating practiced-based learning, such as lab-work, field work or project-based learning would suit all students. Student-centered classes and active leaning are also recommended as being appropriate for all types of student learning styles.
\end{abstract}

Keywords: learning management, learning style, multicultural society, teaching style, active learning

\section{Introduction}

In the three southernmost provinces of Thailand, Yala, Pattani and Narathiwat, the majority of people are Muslim with the remainder being Buddhist, Christian or of other religions. Each group varies in religion, race, way of life, belief, values etc. and this region of Thailand can be considered as hosting a multicultural society (Padungpong \& Yongyuan, 2015). Generally, Muslim people speak Javi, their native language, not Thai, in their daily life, and this is one of the main differences between them and other religious groups. In addition, Muslim parents generally prefer their children to attend Islamic private schools in which the core courses consist of the Arabic language and Islamic studies and where Javi is used for communication in the classroom. As a result, both students and teachers lack Thai language skills. In addition, Islamic teachers usually teach using a teacher-centered methodology in which the teacher is the center of knowledge and controls the learning while the students usually passively receive information with the focus on teaching by reading and writing more than through other methods (Churngchow, Rorbkorb, Petch-urai, Chirtkiatsakul, Waedramae, Saneeyeng, \& Aumchoowatta, 2015). Unfortunately, the lack of Thai language skills causes serious problems with students' academic performance especially on regular courses. This is reflected in the results of the Ordinary National Education Test (ONET), in which high-school students from this region obtain generally lower scores in all regular subjects compared to those from other parts of the country (NIETS, 2018). This may partly result from the lack of Thai language skills since the ONET tests are all conducted in Thai.

After graduation, most high school students from Islamic private schools enter nearby state-run universities where instructors use Thai during the learning process. Since Muslim students cannot use Thai efficiently, the outcome is poor communication between instructors and students. Moreover, differences in learning management between universities and Islamic private schools can also affect the academic achievement of Muslim students in universities (Churngchow \& Sinprajukpol, 2016). Therefore, the results of this study can pave the way for universities to establish appropriate learning management for students of various learning styles at state-run universities in the three southernmost provinces. 


\section{Objectives}

1) To investigate the learning styles of students at the faculties of education within a multicultural society of state-run universities in Thailand.

2) To examine the relationship between students' characteristics, such as academic achievement, discipline, the type of high school they graduated from and the learning styles of students at the faculties of education within a multicultural society of state-run universities in Thailand.

3) To discover appropriate learning management for students with different learning styles at the faculties of education within a multicultural society of state-run universities in Thailand.

\section{Relevant Literature}

Curriculums today generally focus on students' individual differences influenced by a constructivist approach which defines knowledge as temporary, developmental, and socially and culturally mediated, while learners generate knowledge and meanings from an interaction between their experiences and their ideas (Brooks \& Brooks, 1993). One of the individual differences between students is their learning style and the learning modalities through which they learn best. Learning style is commonly taken to mean the preference of students in respect of receiving and processing information. One of the major characteristics of learning style is that it affects how students perceive information, construct it in their minds and accordingly make sense of their environment. Another major characteristic of learning styles is that they develop based on experiences and not on genetic traits (BECTA, 2005). In other words, the preferred learning style may change over time rather than remaining stable, and is independent of both students' abilities and content (Reiner \& Willingham, 2010). Different learning styles mainly focus on different types of information and processing it in various ways (Garcia, Amandi, Schiaffino, \& Campo 2007). Consequently, there are many types of learning style models in the literature and many research instruments have been developed based on those models. Examples of the most popular learning style models in the literature are the perceptual model, the Kolb learning style model, the Dunn and Dunn learning style model, the 4MAT system, the Honey and Mumford learning style model and the Grasha and Riechman learning style model (Kanadli, 2016).

Although in many ways these models seem to be similar to one another there are many differences among them, mostly based on how they distinguish and define different learning styles. For instance, the perceptual learning style model classifies students according to which sensory modality (visual, auditory, kinesthetic), they prefer when perceiving information. Kolb (1984) stated that people perceive information through thinking and feeling (abstract conceptualization and concrete experience) and process it through doing and watching (active experimentation and reflective observation) and this process underlay the formulation of his model. The Dunn and Dunn learning style model identifies five stimuli sources (environmental, emotional, sociological, physiological and psychological) that affect students' learning, and 21 learning style elements across these five stimuli sources (Dunn, 2000). The 4MAT model is based on Kolb's experiential learning model and identifies learning in terms of how people perceive (thinking-sensing) and process (doing-watching) information (McCharty, 1990). The Honey and Mumford learning styles model redefines Kolb's learning cycle according to individuals' experiences of problem solving and decision making (activist, theorist, pragmatist, reflector) (Honey and Mumford, 2006).

Although the theoretic support for Kolb's learning style inventory (LSI) and its validity and reliability have been criticized, Kolb's learning style model is widely accepted. The Kolb learning cycle envisages students building knowledge, skills, values, and attitudes (Kolb \& Kolb, 2005). Kolb's learning style model posits preferences in learning activities characterized by two consecutive phases within the Kolb learning cycle. The different natures of the learning styles in Kolb's model are described by Kolb and Kolb. Divergers prefer to learn through existing in a concrete world and then transforming their experiences through reflective observation. Assimilators prefer to learn through the analysis of concrete phenomena by reflective observation and then making an association or assimilation to create understanding. Convergers prefer to learn from abstract conceptual knowledge and then transforming what they have learned into active experiments. Accommodators prefer a combination of concrete experience or feeling, and active experiments or doing. They tend to gain knowledge through existing in a concrete world and transforming their experiences into active experiments (Sudria, Redhana, Kirn \& Aini, 2018).

Even there are many types of learning style, the Honey and Mumford (1982) inventory of learning styles is one of the most popular models (Kanadli, 2016). Honey and Mumford's learning styles model redefines Kolb's learning cycle (Kolb, 1984) according to individuals' experiences of problem solving and decision making (Honey and Mumford, 2006) and identifies whether someone is predominantly an activist (someone who is better equipped to learn from experience), a reflector (learns better based on reflective observation), a theorist, (learns best from 
exploring associations and interrelationships between ideas and events) or a pragmatist, whose dominant learning activities are those based on doing or trying things that yield practical advantages (De Vita, 2001).

Different learning styles mainly focus on different types of information and processing it in various ways (Garcia, Amandi, Schiaffino, \& Campo 2007). However, there are many types of learning style and the Honey and Mumford (1982) inventory of learning styles is one of the most popular models (Kanadli, 2016). Honey and Mumford's learning styles model redefines Kolb's learning cycle (Kolb, 1984) according to individuals' experiences of problem solving and decision making (Honey \& Mumford, 2006) and identifies whether someone is predominantly an activist (someone who is better equipped to learn from experience), a reflector (learns better based on reflective observation), a theorist, (learns best from exploring associations and interrelationships between ideas and events) or a pragmatist, whose dominant learning activities are those based on doing or trying things that yield practical advantages (De Vita, 2001).

The topic of learning styles continues to be of interest and in the meantime, new aspects have continued to unfold. For instance, Griffiths (2012) noted that learners might employ more than one learning style. Similarly, Zhou (2011) points out that as students might employ an assortment of learning styles, teachers should be prepared to deal with this situation by changing their own teaching styles in order to ensure a good match. Kawai (2010) similarly points out that teachers might have preferred teaching styles, and recommends that they should expand their styles in order to avoid any mismatch between their preferred teaching styles and students' learning styles.

Since cultures are different, it is natural to anticipate differences in the styles of learning in different countries. With growing ethnic and racial diversity in the classroom, instructors need to be aware of cultural biases in the application of teaching and learning practices. Pratt (1992) suggested that university students' learning styles differ across cultures because of the constraints that their cultures place on people's behavioral patterns. The notion that a relationship exists between learning styles and culture has been the subject of academic research for many decades and previous cross-cultural research has revealed that certain ethnic groups have learning styles that are distinct from those of other ethnic groups (Dunn \& Griggs, 1990).

The suggestion of a link between culture and learning styles is not new and many studies have shown that cultural factors influence learning styles. Sywelem, Al-Harbi, Fathema and Witte (2012) found that students of different races such as American, Saudi and Egyptian employed different learning styles. This result was confirmed by De Vita (2001) who found that the students of 20 different nationalities enrolled in her class possessed different learning styles. Furthermore, Goodridge, Lawanto and Santoso (2017) revealed that previous educational experience also affected the learning styles of their students who were learning based on online instruction. Meanwhile, other researchers have found that cultural factors such as age and educational level also influence students' learning styles (Inal, Büyükyavuz, \& Tekin, 2015). Moreover, Sywelem et al., (2012) found that high and low achieving students also employed different learning styles. However, Kanadli, (2016) conducted a meta-analysis to investigate the relationship between leaning styles and academic achievement and found that this relationship was not consistent because it depended on many other cultural factors as well. This result was confirmed by (Sudria, Redhana, Kirna, \& Aini, 2018) who found that learning styles significantly affected achievement for only some types of learning styles.

Knowledge of the relationship between learning styles and academic achievement and that between discipline and learning style can help teachers in various fields of study to design instruction that suits their students' learning styles. Moreover, the relationship between learning styles and types of school curriculums has rarely been investigated and in order to add to the existing research in this area clarifying these three relationships formed the objectives of this study.

\section{Research Methodology}

This study employed a mixed-methods approach in an explanatory design to fulfill the research objectives. The first stage employed quantitative methodology using a survey which explored the learning styles of students in the faculties of education at three state-run universities in the three southernmost provinces. The second stage was conducted using a qualitative approach employing focus group discussions to verify the results from the first stage and, also, to explore the current state of learning management at state-run universities, and to investigate appropriate learning management for students with different learning styles.

\subsection{First Stage - Survey Research}

\subsubsection{Sample}

The sample selected in this study consisted of 642 freshman students from the faculties of education at three state-run universities in the three southernmost provinces of Thailand consisting of Prince of Songkla University, Yala 
Rajabhat University, and Yala Provincial Physical Education College. Of those, 474 participants were female and 168 were male; 425 were Muslim and 217 were Buddhist and their ages ranged from 17 to 23, with all of them being resident in the three southernmost provinces.

\subsubsection{Research Instrument}

The researchers developed a learning styles inventory (LSI) in the form of a questionnaire based on Honey and Mumford (2006) which classified learning styles into four types: reflectors, theorists, pragmatists and activists. The researchers developed 20 statements in each category relating to learning behavior, representing the type of learning style to which that statement was relevant. There were therefore a total of 80 items. Moreover the researchers constructed the items in such the way that they were appropriate for the multicultural society in the three southernmost provinces, in which most students are either Muslims or Buddhists.

The construct validity of this instrument was verified employing the Q-sort Technique. Under this technique, an expert is given a set of statements on cards, and asked to place them into categories corresponding to the specific types of characteristics being investigated (McKeown \& Thomas, 1988). For this study, three senior professors from the disciplines of psychology and education from different universities were assigned to be the expert group. Each expert was presented with an envelope containing four header cards labeled: reflectors, theorists, pragmatists and activists in keeping with the four domains that the instrument attempted to measure. The envelope also contained the instrument's 80 statements on individual slips of paper. The experts were then requested to array the header cards in front of them and place the statements with the appropriate header card. Upon completion, the statements were paper-clipped to the header cards and returned to the envelope.

The resulting arrangements were reviewed for percentage agreement with the instruments' scoring standards. It was found that all three experts judges all 80 statements in the same way with the, four types of learning-styles containing 20 statements each. This process therefore verified the construct validity of the LSI.

In using the LSI, for each statement the respondents were asked to consider whether or not it described his/her own learning behavior. Students who answered "yes" were assigned one point for that statement, or zero if his/her answer was "no". The type of learning style which obtained the highest score was taken to indicate the learning style to which that respondent belonged. However, it is worth stressing that this inventory was adapted based on local language and culture, and the administrations of this LSI would only be appropriate for students in Thailand's three southernmost provinces.

\subsubsection{Data Collection}

Two lecturers from Yala Rajabhat University volunteered to distribute the LSI to all the participants and to collect them and return them to the researchers. All 683 freshmen from the faculties of education at the three state-run universities were requested to voluntarily fill out the LSI and 642 completed LSIs (359, 196 and 87 respectively from Prince of Songkla University, Yala Rajabhat University and Yala Provincial Physical Education College) were returned to the researchers representing a return rate of $94 \%$.

\subsection{Second Stage - Focus Group}

Based on the results from the first stage, the researchers set up focus group discussions at all three state-run universities. The participants were divided into four groups, activists, reflectors, theorists and pragmatists. At each institution, the students in each group with the five highest scores within each type of learning style were selected as representatives of their learning style and invited to participate in the focus group discussions. Therefore, the total number of participants from the three institutions was 60, with 15 participants representing each learning style. All of them were invited to participate focus group with approval from their universities. At the beginning of the focus group discussion, aspects of ethical research relating to the issues of voluntary participation, privacy, anonymity, confidentiality, physical and psychological harm, debriefing, and informed consent were given due attention. The students were given ample time to reflect on and withdraw from the study if they felt uncomfortable with the purpose and objectives of the research, all the participants agreed to participate in the study. The participants were predominantly female and Muslim, aged between 17-20, and came from various fields of study such as social sciences, health sciences, physical science or related fields with a small number from natural sciences or mathematics. Three researchers attended the discussions, one as the moderator and two as note-takers. During the focus group discussions, two issues were raised. First, in order to revalidate the construct validity of the leaning style inventory, the participants were asked to comment on whether or not their learning behavior was actually as described by the definition of the type of learning style to which they had been assigned. Secondly, they were asked to describe the current methods of teaching and learning employed in their university and to discuss the types of learning 
management they thought best matched their learning styles. During the discussion, the moderator and two note-takers recorded the conversation simultaneously for later analysis. Triangulation was employed to guarantee the validity of the data, (Ary, Jacobs \& Soronsen, 2010) with the two note-takers first comparing their accounts of the conversations and producing a commonly agreed version which was then presented to the moderator for validation. In this way the researchers were able to arrive at an accurate account of the conversations and were then able to analyze the data from the focus group discussions.

\section{Results}

\subsection{Results of the Survey}

Table 1. Participants classified by discipline and type of learning style

\begin{tabular}{ccccccc}
\hline & & \multicolumn{3}{c}{ Learning Styles } \\
& & Activists & Reflectors & Theorists & Pragmatists & Total \\
\hline Science and & Number & 8 & 52 & 21 & 14 & 95 \\
Technology & Percentage & $8.42 \%$ & $54.74 \%$ & $22.10 \%$ & $14.74 \%$ & $100.00 \%$ \\
Mathematics & Number & 2 & 22 & 1 & 3 & 28 \\
& Percentage & $7.14 \%$ & $78.57 \%$ & $3.57 \%$ & $10.72 \%$ & $100.00 \%$ \\
Social Sciences & Number & 46 & 162 & 99 & 68 & 375 \\
& Percentage & $12.27 \%$ & $43.20 \%$ & $26.40 \%$ & $18.13 \%$ & $100.00 \%$ \\
Humanities & Number & 18 & 72 & 31 & 23 & 144 \\
& Percentage & $12.50 \%$ & $50.00 \%$ & $21.53 \%$ & $15.97 \%$ & $100.00 \%$ \\
Total & Number & 74 & 308 & 152 & 108 & 642 \\
& Percentage & $11.53 \%$ & $47.97 \%$ & $23.68 \%$ & $16.82 \%$ & $100.00 \%$ \\
\hline$\chi^{2}=17.479 \quad \mathrm{df}=9$ & $\mathrm{P}<.042$ & & & & &
\end{tabular}

As can be seen from Table 1, most of the students were reflectors (47.97\%) with the second largest group being theorists $(23.68 \%)$. However, the proportion of reflectors was highest for those studying mathematics (78.57\%), and lowest for those studying social sciences $(43.20 \%)$, indicating that while most students were reflectors there a differences by discipline with mathematics students being more likely to be reflectors than students from other disciplines. Moreover, chi-square tests showed that the numbers of students with particular learning styles across subject areas were significantly different at the $\mathrm{p}<.05$ level.

Table 2. Participants classified by their type of high school and learning style

\begin{tabular}{ccccccc}
\hline & & \multicolumn{3}{c}{ Learning Styles } \\
& & Activists & Reflectors & Theorists & Pragmatists & Total \\
\hline Public and Regular & Number & 35 & 147 & 46 & 35 & 263 \\
Private Schools & Percentage & $13.31 \%$ & $55.89 \%$ & $17.49 \%$ & $13.31 \%$ & $100.00 \%$ \\
& Number & 39 & 161 & 106 & 73 & 379 \\
Islamic Private Schools & Percentage & $10.29 \%$ & $42.48 \%$ & $27.97 \%$ & $19.26 \%$ & $100.00 \%$ \\
& Number & 74 & 308 & 152 & 108 & 642 \\
Total & Percentage & $11.53 \%$ & $47.98 \%$ & $23.67 \%$ & $16.82 \%$ & $100.00 \%$ \\
\hline
\end{tabular}

$\chi^{2}=17.520 \quad \mathrm{df}=3 \quad \mathrm{P}<.001$

Table 2 shows that there was a difference in learning styles based on type of high school with students from public schools being more likely to be reflectors than students from Islamic private schools and chi-square tests also indicated that public schools produced significantly different proportions of each type of learning style to Islamic private schools at the $\mathrm{p}<.01$ level.

To compare academic achievement among the four groups with different learning styles, ANOVA was employed and it was found that their academic achievement was not significantly different $(\mathrm{F}=1.706 \quad \mathrm{df}=3,638 \quad \mathrm{P}>.05)$. 


\subsection{Results from Focus Group Discussions}

The results from the focus group discussions showed that the students assigned to the four kinds of learning style accepted that their learning approaches were actually the same as extracted from the use of the LSI. The participants also described the current learning management in the state-run universities in the three southernmost provinces, with lecturing being the most widely-used teaching method. Meanwhile, it was noted that universities lack instruction material for students of all kinds of learning styles, such as laboratories, textbooks, videos, and modern equipment such as media suitable for e-learning or mobile learning. The groups of participants also suggested that their universities should provide learning material and media to complement their learning styles, as follows:

Reflectors would like more up-to-date media such as e-learning materials produced by well-known private companies rather than government authorities. They learn better based on thought processes and prefer to review previous experience, collect data and think carefully before making any decision. They do not like listening to the teacher for a long time nor practicing immediately without understanding theory. They like to practice or conduct activities as soon as possible after a lecture session has finished.

"some instructors lecture for too long and make me late for the following class, they had better focus on vital points only" (student A)

"instructors should provide sufficient background knowledge before going to the next step, otherwise student $\mathrm{s}$ get confused at the later part" (student B)

"Even though I am classified as a reflector by the questionnaire, my learning behavior also corresponds to that of a pragmatist" (student C)

Theorists suggested that institutions should provide a greater variety of learning material and media and give priority to activity or project-based learning rather than only providing lecture-based classes. They prefer to learn by planning in advance and do not want to make any decision without having sufficient background knowledge. They want to practice immediately after a theoretical session is finished to observe the actual outcome.

"all of our textbooks and materials are obsolete, we need more advanced and hi-tech materials" (student D)

"instructors should reduce lecture time and add extra time and provide more meeting rooms for students to discuss their own projects" ( student E)

Pragmatists wanted institutions to have small classes to make it easier for learners to discuss together and they need a greater variety of learning facilities, such as more laboratory space and modern learning material and equipment. They prefer learning-by-doing rather than learning based only on theory, and prefer to practice and comprehend theories simultaneously then make a decision quickly without learning the theory beforehand. They like to learn based on student-centered approaches such as project-based learning and self-directed learning and working. In addition, they prefer to conduct new experiments on their own with limited advice from instructors.

"university should provide sufficient labs and learning media for all of us" (student F)

"learning media and materials in lab should be real rather than artificial materials such as human skeleton or skull etc." (student G)

Activists wanted their institutions to provide more space for group meetings or discussions, and learning material and media appropriate for active learning, such as computers and other forms of information technology. They also requested that instructors should be brief and conclude their lectures without providing too many details. This group prefers to learn by themselves or in a group but they need some suggestions or discussion before working and do not want to work only based on orders from instructors.

"we prefer teaching methods which enable us to study by ourselves such as project-based learning, lab work or field work rather than lecturing" (student $\mathrm{H}$ )

"for every project, we need instructors to attend every time of group discussion to advise when we have problems" ( student I)

However, most students, especially the Muslim students, said that they behaved as pragmatist learners as well as employing the predominant learning style to which they were assigned based on the LSI, or were found to be bimodal. 


\section{Discussion}

The students from the faculties of education fell into the four types of learning style included in the Honey and Mumford model (1982). This result supports the findings of Coffield et al., (2004) who suggested that all people can be classified according to their learning styles. It was also found that learning styles varied across subject areas with, for instance, most students in the field of mathematics being reflectors. However, the largest numbers of students in other subject areas, such as social science and the humanities were also reflectors, although the proportion in other groups was not as high as for mathematics. This result was in agreement with Honey and Mumford (2006) finding relating to learning styles, that mathematics students obtain information through abstract conceptualization and solve problems based on existing theories. Since reflectors are learners who seek practical applications of thoughts and ideas, they focus on solving problems and they prefer situations which have only a single correct answer. Moreover, they prefer to focus on objects rather than individuals (Aydın, 2016).

In addition, there was a higher proportion of reflectors among students from public schools than those from Islamic schools. This finding might result from differences in the subjects taught between Islamic private schools and public schools. In Islamic schools, teachers usually focus on Islamic principles, which students need to comprehend and practice in daily life based on the dictates of Islam. Moreover, most teachers lack teaching skills since they do not graduate from either colleges of education or similar institutions (Churngchow et al., 2015). Meanwhile, public schools focus on regular subjects such as mathematics, English and natural sciences. In Islamic private schools, a teacher-centered approach is employed rather than a student-centered approach, as is adopted in public schools. A teacher-centered teaching style would not match the learning styles of activist and pragmatist students. On the other hand, a student-centered approach would be preferred by most students since this approach is better suited to each of the learning styles. The results also showed that learning styles were not related to academic achievement which agreed with Keefe and Ferrell (1990) findings. This is because academic achievement depends more on cognitive processes than on learning styles. This finding was in contrast to some previous studies which have found that students learn more effectively (e.g. increase their academic achievement and have positive attitudes toward learning) in a context where the instructional design matches their learning style. Kanadli (2016) found that the average student receiving instruction tailored to their learning style scored higher on achievement tests than students who did not receive such matched instruction.

Based on the focus group discussions, there were clear differences between students with different learning styles in terms of the strategies they would like to see implemented by teachers. This finding supports that of De Vita (2001) who found that instructors should provide different in learning management according to students' different learning styles, such as focusing on reflection and evaluation for reflectors, group projects, brainstorming, learning-by-doing and problem-solving exercises for activists, theories and models, space for abstraction and conceptualization for theorists, and case studies, examples and explicit links to the real world for pragmatists. Most Muslim students were found to be partially pragmatic, which might reflect their problems in reading, speaking, and writing Thai which might tend to make them more likely to prefer learning by practicing rather than through those mediums. Students can achieve course objectives based on practice-related learning regardless of literacy in the Thai language since they can conduct the learning process by themselves and this might induce most Muslim students to become partially pragmatic.

In order to match learning management with the course structure, content and context, it may be better to divide classes into small groups based on students' learning styles. However, class size and the particular learning styles of individual students should be considered by teachers before making decisions, and if separate groups are more appropriate, students' learning styles should be determined before classes begin (Lauria, 2010). Furthermore, most students employ a pragmatic style at some time, and thus practice-based learning, such as lab-work, field work or project-based learning should be employed for students in all the learner-style groups. This is supported by Sudria et al., (2018) who found that lab-work was fruitful for learners of all learning styles. However, instructors should recognized that different learning styles may be useful for different tasks and can change over time.

Therefore, the state-run universities in the three southernmost provinces should establish learning management suitable for the pragmatic learning style, such as conducting more lab-work, field studies or projects because even though pragmatists were not the majority group the fact that many learners from other styles also adopted the pragmatic style from time to time made this a very important learning style. However, to suit all kinds of student learning styles, all courses should be designed based on student-centered or self-directed approaches. 


\section{Conclusion}

It can be concluded that students at the faculties of education at the state-run universities sampled demonstrated all four learning styles: theorist, pragmatist, activist and reflector, while reflectors formed the largest group. However, many students indicated that they employed the pragmatist learning style in addition to their dominant style. The results also showed that there were significant differences in the learning styles employed by students from different disciplines and types of high school. It is suggested that students should be assisted to understand their learning styles in order to optimize the use of strategies that suit their style in order to succeed at university and moreover that the teaching practices offered should support this. However, course content, class size and particular individual styles should be considered by teachers before designing the form of instruction which best matches their students' learning styles. However, a teaching style suited to the pragmatist learning style incorporating practiced-based learning may be appropriate for all students and future research on appropriate learning management to suit students with bimodal learning styles within a multicultural society is recommended.

\section{Acknowledgements}

The authors are grateful for a grant from the Research Fund of Prince of Songkla University, Pattani campus, to support this research.

\section{References}

Ary, D., Jacobs, L. C., \& Sorensen, C. (2010). Introduction to research in education (8th ed.). CA: Wadsworth.

Aydin, S. (2016). A qualitative research on foreign language teaching anxiety. The Qualitative Report, 21(4), 630-642.

BECTA. (2005). Learning styles-an introduction to the research literature. Retrieved on May 1, 2018 from http://dera.ioe.ac.uk/14118/1/learning_styles.pdf.

Brooks, J. G., \& Brooks, M. G. (1993). In search of understanding: the case for constructivist classrooms. Alexandria, VA: Association for Supervision and Curriculum Development.

Churngchow, C., Rorbkorb, N., Petch-urai, O., Chirtkiatsakul, B., Waedramae, M., Saneeyeng, R., \& Aumchoowatta, Y. (2015). A model for the development of the teaching efficiency ofreligious teachers in Islamic private schools in the three southernmost provinces of Thailand. Journal of Social Sciences Research, 8(2), 1573-1585. https://doi.org/10.24297/jssr.v8i2.3726

Churngchow, C., \& Sinprajukpol, W. (2016). Factors affecting the scholastic achievement of Prince of Songkla University students from private schools with Islam instruction in the Three southern border provinces. Kasetsart Journal of Social Sciences, 37(1), 59-65.https://doi.org/10.1016/j.kjss.2016.01.001

Coffield, F., Moseley, D., Hall, E., \& Ecclestone, K. (2004). Learning styles and pedagogy in post-16 learning: A systematic and critical review. Retrieved on February 23, 2018 from http://sxills.nl/lerenlerennu/bronnen/Learning.

De Vita, G. (2001). Learning styles, culture and inclusive instruction in the multicultural classroom: A business and management perspective. Innovations in Education and Teaching International, 38(2), 165-174. https://doi.org/10.1080/14703290110035437

Dunn, R. (2000). Learning styles: Theory, research, and practice. National Forum of Applied Educational Research Journal, 13(1), 3-22.

Dunn, R., \& Griggs, S. A. (1990). Research on the learning style characteristics of selected racial and ethnic groups. Journal of Reading, Writing, and Learning Disabilities, 6(5), 261-280. https://doi.org/10.1080/0748763900060305

Garcia, P., Amandi, A., Schiaffino, S., \& Campo, S. (2007). Evaluating Bayesian networks' precision for detecting student's learning styles. Computers \& Education, 49, 794-808. https://doi.org/10.1016/j.compedu.2005.11.017

Griffiths, C. (2012). Learning styles: traversing the quagmire. In S. Mercer, S. Ryan, \& M. Williams (Eds.). Psychology for language learning: insights from research, theory and practice. London: Palgrave Macmillan, 151-16. https://doi.org/10.1057/9781137032829_11

Goodridge, Lawanto, O., \& Santoso, H. (2017). A learning style comparison between synchronous online and face-to-face engineering graphics instruction. International Education Studies, 10(2), 1-14. https://doi.org/10.5539/ies.v10n2p1 
Honey, P., \& Mumford, A. (1982). The Manual of Learning Styles. Peter Honey, Maidenhead.

Honey, P., \& Mumford, A. (2006). The Learning Styles Questionnaire, 80-item version. Maidenhead, UK: Peter Honey.

Inal, S., Büyükyavuz, O., \& Tekin, M. (2015). A study on preferred learning styles of Turkish EFL teacher trainees. Australian Journal of Teacher Education, 40(3), 52-67. https://doi.org/10.14221/ajte.2014v40n3.4

Kanadl1, S. (2016). A meta-analysis on the effect of instructional designs based on the learning styles models on academic achievement, attitude and retention. Educational Sciences:Theory \& Practice, 16, 2057-2086.

Kawai, Y. (2010). Learner variability-learning styles. In H. Kojima, N. Ozeki, \& T. Hiromori (Eds.), A series of studies on English Education, pp.19-43.

Keefe, J. W., \& Ferrell, B. G. (1990). Developing a defensible learning style paradigm. Educational Leadership, 2 , 57-61.

Kolb, D. A. (1984). Experiential learning: Experience as the source of learning and development. New Jersey, NJ: Prentice-Hall.

Kolb, A., \& Kolb, D. (2005). The Kolb learning style inventory - version 3.12005 Technical specifications. London: Hay Resources Direct.

Lauria, J. (2010). Differentiation through learning- style responsive strategies. Kappa Delta Pi record, 47(1), 24-29. https://doi.org/10.1080/00228958.2010.10516556

McCharty, B. (1990). Using the 4MAT System to bring learning styles to school. Association for Supervision and Curriculum Development. Retrieved from http://www.ascd.org/ASCD/pdf

McKeown, B.F., \& Thomas, D.B. (1988). $Q$ - Methodology. Newbury Park. CA: Sage Publications. https://doi.org/10.4135/9781412985512

National Institute of Education Testing Service (NIETS). (2018). Announcement of ONET scores. Retrieved on May 30, 2018 from http://www.niets.or.th/th/catalog/view/2989.

Pashler, H., McDaniel, M., Rohrer, D., \& Bjork, R. (2008). Psychological science public interest, 9(3), 105-119. https://doi.org/10.1111/j.1539-6053.2009.01038.x

Padungpong, C., \& Yongyuan, B. (2015). The effects of art activities on respect for cultural diversity of secondary school students with different classroom components. Songklanakarin Journal of Social Sciences and Humanities, 2l(1), 169-200.

Pratt, D. (1992). Conceptions of teaching. Adult Education Quarterly, 42, 203-220. https://doi.org/10.1177/074171369204200401

Reinre.C., \& Willingham, D. (2010). The myth of learning styles. Change: The magazine of higher learning, 42(5), 32-35. https://doi.org/10.1080/00091383.2010.503139

Riding, R. (2005). Individual differences and educational performance. Educational Psychology, 25(6), 659-72. https://doi.org/10.1080/01443410500344712

Reynolds, M. (1997). Learning styles: A critique. Management Learning, 28, 115-133. https://doi.org/10.1177/1350507697282002

Sudria, I. B. N., Redhana, I W., Kirna, I M., \& Aini, D. (2018). Effect of Kolb's learning styles under inductive guided-inquiry learning on learning outcomes. International Journal of Instruction, 11(1), 89-102. https://doi.org/10.12973/iji.2018.1117a

Sywelem, M., Al-Harbi, Q., Fathema, N., \& Witte, J. (2012). Learning style preferences of student teachers: A cross-cultural perspective. Institute for Learning Styles Journal, 1(Spring 2012), 10-24.

Zhou, M. (2011). Learning styles and teaching styles in college English teaching. International Education Studies, 4(1). Retrieved on May 10, 2018 from http://dx.doi.org/10.5539/ies.v4n1p73. 